\title{
High-NaCl Perception in Drosophila melanogaster
}

\author{
(ㄷ)Georges Alves, Jérémy Sallé, Sylvie Chaudy, Stéphane Dupas, and Gérard Manière \\ Centre des Sciences du Goût et de l'Alimentation, UMR-6265 CNRS, UMR-1324 INRA, Université de Bourgogne, 21000 Dijon, France
}

\begin{abstract}
Salt is a fundamental nutrient that is required for many physiological processes, including electrolyte homeostasis and neuronal activity. In mammals and Drosophila, the detection of $\mathrm{NaCl}$ induces two different behaviors: low-salt concentrations provide an attractive stimulus, whereas high-salt concentrations are avoided. We identified the gene called serrano (sano) as being expressed in the sensory organs of Drosophila larvae. A transgenic reporter line showed that sano was coexpressed with Gr66a in a subset of gustatory neurons in the terminal organ of third-instar larvae. The disruption of sano gene expression in gustatory neurons led to the specific loss of high-salt concentration avoidance in larvae, whereas the detection of other attractive or aversive substances was unaffected. Moreover, using a cellular marker sensitive to calcium levels, Sano function was shown to be required for neuronal activity in response to high-salt concentrations. In these neurons, the loss of the DEG/ENaC channel PPK19 function also eliminated the cellular response to high-salt concentrations. Our study revealed that PPK19 and Sano are required in the neurons of the larval gustatory organs for the detection of high-salt concentrations.
\end{abstract}

Key words: behavior; chemosensory system; Drosophila melanogaster; larva; salt; taste

\section{Introduction}

Gustatory information is considered to be important for the control of animal behaviors, such as searching for food or sexual partners. In Drosophila, larvae sense olfactory and gustatory cues with the three major chemosensory organs located on the head surface, dorsal organ (DO), terminal organ (TO) and ventral organ (VO), and three pharyngeal organs (Vosshall and Stocker, 2007). Olfactory receptor neurons located in the DO project into glomeruli of the antennal lobe, whereas gustatory receptor neurons (GRNs) project via four different nerves to the suboesophageal ganglion (Vosshall and Stocker, 2007).

Insects, like mammals, are able to detect and discriminate among different gustatory stimuli, such as sugars, bitter substances, and salts, that can induce an attractive or a repulsive response in behavioral tests. Electrophysiological studies performed on Drosophila adult taste sensilla have revealed that low- and high- $\mathrm{NaCl}$ concentrations are detected by two distinct gustatory neurons (Hiroi et al., 2004; Amrein and Thorne, 2005; Ishimoto and Tanimura, 2004). Larvae are also able to display an

Received Nov. 14, 2013; revised June 23, 2014; accepted June 27, 2014

Author contributions: G.A. and G.M. designed research; G.A., J.S., S.C., S.D., and G.M. performed research; G.A. and G.M. contributed unpublished reagents/analytic tools; G.A., J.S., and G.M. analyzed data; G.A. and G.M. wrote the paper.

This work was supported by grants from the National Center of Scientific Research and the Regional Council of Burgundy (PARI, Regional Action Plan for Innovation). We thank Isabelle Chauvel for technical assistance and Yann Roche and Christine Arnould from the Diamacell platform for spectral image analysis and technical assistance for the confocal microscopy.

The authors declare no competing financial interests.

Correspondence should be addressed to Dr. Georges Alves, Centre des Sciences du Goût et de l'Alimentation, UMR-6265 CNRS, UMR-1324 Institut National de la Recherche Agronomique, Université de Bourgogne, 9E boulevard Jeanne d'Arc, 21000 Dijon, France. E-mail: georges.alves@u-bourgogne.fr.

J. Sallé's present address: Génétique et Biologie du Développement, Institut Curie, UMR-3215 CNRS, INSERM U934, 26, rue d'Ulm, 75248 Paris Cedex 05, France.

DOI:10.1523/JNEUROSCI.4795-13.2014

Copyright $\odot 2014$ the authors $\quad 0270-6474 / 14 / 3410884-08 \$ 15.00 / 0$ attractive behavior in response to low-salt concentrations and an aversive response in the presence of high-salt concentrations (Heimbeck et al., 1999; Balakireva et al., 2000; Gerber and Stocker, 2007; Niewalda et al., 2008; Russell et al., 2011). The $d p r$ locus (for defective proboscis extension response), a member of the Ig superfamily, is required for the aversive response to highsalt concentrations in adult flies (Nakamura et al., 2002). Two members of the pickpocket ( $p p k$ ) gene family (DEG/ENaC channels, $p p k 19$ and $p p k 11$ ) have been implicated in the responses to low- and high- $\mathrm{NaCl}$ concentrations (Liu et al., 2003). In mammals, the detection of $\mathrm{NaCl}$ also requires the expression of $\mathrm{ENaC}$ protein in a subset of the taste receptor cells in the taste buds (Chandrashekar et al., 2010). More recently, Zhang et al. (2013) suggested that $\mathrm{NaCl}$ perception in Drosophila adults is determined by a bimodal switch system operating in GRNs that allows for detecting separately low- and high- $\mathrm{NaCl}$ concentrations. Moreover, they demonstrated that the ionotropic channel IR76b is selectively involved in the attractive pathway.

In this study, we describe the serrano (sano) locus, which we identified by the specific loss of the aversive response to high$\mathrm{NaCl}$ concentrations in the mutant larvae; the responses to other attractive (sucrose or low- $\mathrm{NaCl}$ concentrations) and aversive (caffeine) stimuli remained unaltered. The sano locus encodes a putative cytoplasmic protein of 778 aa, which is related to the Themis gene family (Chung et al., 2009; Johnson et al., 2009). In our study, we show that Sano function is specifically required in the larval peripheral nervous system for the detection of high- $\mathrm{NaCl}$ concentrations and the subsequent induction of aversive behavior. Moreover, we show that Sano is necessary for neuronal activity of GRNs present in the TO of the larvae in response to high salt. Thus, Sano plays a key role in the detection of high- $\mathrm{NaCl}$ concentrations through the gustatory neurons of the TO. 


\section{Materials and Methods}

Fly strains. The fly strains used in this study were the wild-type strain CantonS, the $s a n o^{G a l 4}$ strain (identified from lines generated in a previous screen and provided by Prof. Denise Busson, Université Pierre et Marie Curie, Paris, France), the sano ${ }^{G E 12233}$ and sano ${ }^{G E 15762}$ strains (purchased from Genexel), and the UAS-TNT (tetanic toxin light chain), 10XUAS-IVS- $m$ CD8::GFP, 10XUAS-IVS-mCD8::RFP, tubP-Gal80 ${ }^{t s}$, and UAS-Cameleon2.1 (Cam2.1) strains (from the Bloomington Stock Center). The UAS-ppk19dsRNA strain was kindly provided by Dr. Michael J. Welsh (Howard Hugues Medical Institute, University of Iowa, Iowa City, IA). The Gr66a-GFP and Gr66a $a^{\text {Gal4 }}$ strains were kindly provided by Dr. Kristin Scott (Howard Hugues Medical Institute, University of California, Berkeley, Berkeley, CA) and Dr. Hubert Amrein (Texas A\&M Health Science Center, College Station, TX), respectively. The strains used in behavioral tests have been outcrossed to a $w^{1118}$ strain for five generations.

The generation of transgenic flies. The sano ORF was amplified from the cDNA clone RE56731 (Berkeley Drosophila Genome Project), which contained the full RB cDNA, and was cloned into the pGEM-T vector for sequencing and into the pUAST vector to generate the UAS-sano lines.

A fragment of $575 \mathrm{bp}$ from the exon 7 sequence was amplified from the cDNA clone RE56731 with the primers $5^{\prime}$-tctagaaactgcgactgctgggctgc and $5^{\prime}$-tctagacggaggtggtggcctgctgg and cloned into the pGEM-T vector for sequencing. Then, the fragment was cloned into the pWIZ vector to generate the UAS-sano ${ }^{d s R N A}$ strain (protocol as in the study by Lee and Carthew, 2003). The construct was introduced into the Drosophila germ line by injection into $w^{1118}$ embryos of either sex, as described previously (Rubin and Spradling, 1982).

Larval behavioral assay. Petri dishes $(9.5 \mathrm{~cm}$ diameter $)$ were divided into two compartments. Each compartment was filled with either $2 \%$ agarose/water (control) or 2\% agarose/test solution mixed in water (sucrose; S0389; Sigma-Aldrich), quinine (quinine hydrochloride; Q1125; Sigma-Aldrich), caffeine (C0750; Sigma-Aldrich), and sodium chloride (S9625; Sigma-Aldrich). At $t=0$ min, 50 early-to-mid L3 larvae of either sex were placed on the dividing line between the two zones and allowed to move freely. The number of larvae found on the control (Nc) and test $(\mathrm{Nt})$ areas was counted at $10 \mathrm{~min}$. The larvae found at a distance of $<0.5$ $\mathrm{cm}$ on either side of the dividing line were not included in the index calculation. A gustatory preference index (GPI) was calculated using the following formula: GPI $=(N \mathrm{t}-\mathrm{Nc}) /(\mathrm{Nt}+\mathrm{Nc})$. Positive preference indices indicate an attractive behavior, whereas negative ones indicate avoidance behavior toward tested substances. For each test, $n=10$.

$R T-P C R$. RNA was extracted from various portions of the dissected larvae of either sex using the TRIzol reagent (Invitrogen) and treated with RNasefree DNase to eliminate contamination by genomic DNA. Total RNA $(1 \mu \mathrm{g})$ was reverse transcribed using the iScript cDNA Synthesis kit (Bio-Rad).

PCR reactions were conducted using a thermocycler (Bio-Rad). PCR primers were designed for different exons of the sano coding region (see Fig. 2): forward 1 (exon 1), 5' -ctgcgtctctttgcgtgttgg; forward 2 (exon 2), $5^{\prime}$-gaagccggtttcgtttctgtgtc; forward 3 (exons $5 \mathrm{a}$ and $5 \mathrm{~b}$ ), $5^{\prime}$-cggttcggtgtgtcccattgc; forward 4 (exon 5b), $5^{\prime}$-ggtatcagcgtgtgtttcgtcac; forward 5 (exon 8), $5^{\prime}$-acaacaattgctcctctgtgacg; reverse 1 (exon 6), $5^{\prime}$-ctcctttcgattccctttgacgc; reverse 2 (exon 8), 5' -atggcagctagaaacgagttggc; and reverse 3 (exon 9), $5^{\prime}$-cgattgcgagcagatggg.

Real-time PCR. RNA from the various genotypes was extracted from 80 anterior portions of the third-instar larvae of either sex and treated with DNase to eliminate contamination by genomic DNA. The standard protocol was used for real-time PCR (Applied Biosystems, Roche). PCR primers were designed for the region spanning from exon 6 to exon 7: sano exon 6 forward, 5' -ggtgtccacaccgtcaaga; and sano exon 7 reverse, $5^{\prime}$-cactgccgtgaacgagtct.

Fluorescence and calcium imaging. For GFP and RFP expression imaging, the anterior part of the larvae was dissected and incubated in a glycerol/1 $\times$ PBS (50:50) mix for $1 \mathrm{~h}$ and mounted in Vectashield mounting medium (Kwon et al., 2011). Then direct observation of the fluorescence was performed using a confocal microscope (Leica TCS SP2).

For calcium imaging, living larvae of either sex were placed in $25 \mu \mathrm{l}$ of distilled water between a cover slide and a perforated slide. The prepara- tion was placed on an inverted confocal spectral Nikon C1Si microscope and observed with a $40 \times$ objective. Then, $25 \mu$ l of distilled water, $25 \mu \mathrm{l}$ of $20 \mathrm{~mm} \mathrm{NaCl}$ (to obtain a final concentration of $10 \mathrm{~mm} \mathrm{NaCl}$ ), or $25 \mu \mathrm{l}$ of $600 \mathrm{~mm} \mathrm{NaCl}$ (to obtain a final concentration of $300 \mathrm{~mm} \mathrm{NaCl}$ ) was injected through the hole in the slide. The fluorescence images (2 frames/s, $96 \times 96$ pixels) were acquired simultaneously using the Nikon EZ-C1 acquisition software and were analyzed using the Nikon EZ-C1 FreeViewer software. The FRET changes were measured as the ratio $(R)$ of the donor over the acceptor emission intensities $(427 \mathrm{~nm} / 527 \mathrm{~nm})$ and expressed as a percentage increase over the mean of the $R$ values obtained during the measurement $(\Delta R / R 0 \%)$. Data are expressed as the mean \pm SEM.

Statistical analysis. For each experiment, data were presented as mean \pm SEM. All statistical analyses were performed with Prism 5 software for Mac OSX (GraphPad Software). Statistical analysis was generally made using either Student's $t$ test or, for multiple comparisons, one-way ANOVA, followed by Bonferroni's post hoc test. $p$ values $<0.05$ were considered to be statistically significant.

\section{Results}

\section{Identification of the sano gene}

We identified the sano gene from a genetic screen of a P-Gal4 insertion collection based on both expression in larval chemosensory organs and the gustatory choice behavior defects observed in viable homozygous mutants. Among several selected lines, one P-Gal4 line (later called sano ${ }^{\text {Gal4 }}$ ), when combined with 10XUAS-IVS-mCD8::GFP, showed expression in a few GRNs $(5.5 \pm 0.24 ; n=10)$ in the TO and in three neurons in the ventral pharyngeal sense organ (VPS) of third-instar larvae (Fig. $1 A a, A b)$. We also observed expression in a few neurons along the body. Then, we studied gustatory choice behavior on early thirdinstar sano mutant larvae with different attractive (100 mM sucrose) or aversive (10 $\mathrm{mm}$ caffeine and $10 \mathrm{~mm}$ quinine) substances and $\mathrm{NaCl}$ at different concentrations ranging from 10 to $500 \mathrm{~mm}$. In a dose-response behavioral analysis toward $\mathrm{NaCl}$, we observed that the homozygous larvae from the three mutant strains $\left(\right.$ sano $^{\text {Gal4 }}$, sano $^{G E 12233}$, and sano ${ }^{G E 15762}$ ) showed a response to low-salt concentrations (at 10 and $50 \mathrm{~mm} \mathrm{NaCl}$ ) similar to that observed for wild-type or sano ${ }^{\text {Gal4}} /+$ (Fig. 1B). At $100 \mathrm{~mm} \mathrm{NaCl}$, sano mutant larvae displayed an attractive response, whereas wild-type larvae showed no preference. For higher $\mathrm{NaCl}$ concentrations $(200,300$, and $500 \mathrm{~mm})$, mutant larvae showed strong defects in the aversion to $\mathrm{NaCl}$. To verify that the behavioral defect was related to the reduction of sano expression, we generated a UAS-sano construct containing the cDNA of the RB transcript and introduced it into a sano ${ }^{\text {Gal }}$ mutant background (Fig. $2 A)$. The defects in aversion could then be rescued; therefore, these defects are likely attributable to sano misexpression (Fig. $1 B)$. sano mutant larvae, such as wild-type larvae, were attracted by $100 \mathrm{~mm}$ sucrose and were repelled by $10 \mathrm{~mm}$ caffeine or $10 \mathrm{~mm}$ quinine, showing that the GRNs of the mutant larvae were functional and could detect other aversive and attractive substances (Fig. 1C).

Using PCR, we located the P-Gal4 insertion 104 bp upstream of a transcription start site for CG12758 (serrano). Five transcripts (RA, $\mathrm{RB}, \mathrm{RC}, \mathrm{RD}$, and $\mathrm{RE}$ ) were predicted, with at least two transcription start sites separated by $70 \mathrm{~kb}$ (Fig. 2A). All of the transcripts code for the same predicted protein of 778 aa. The Sano protein is a member of the uncharacterized Themis protein family (Chung et al., 2009; Johnson et al., 2009). Members of this family are present in animals from cnidarians to mammals and contain at least one cysteine-rich CABIT domain and a low-complexity proline-rich stretch (Chung et al., 2009; Johnson et al., 2009). In Drosophila, Sano interacts with Dishevelled, a planar cell polarity regulator, to control tracheal tube length during development (Chung et al., 2009). 
The sano coding region spans over 80 $\mathrm{kb}$ and contains a second predicted transcription start site. To determine whether some of the putative transcripts were specifically present in the larval chemosensory organs, we examined sano expression by RT-PCR in several larval tissues. To detect the different transcripts, we selected specific primers located in exons spanning other introns (Fig. 2A). The combination of different primers allowed for the amplification of the cDNA fragments corresponding to each transcript. At least four sano transcripts (RA, RB, RC, and $\mathrm{RD}$ were detected, but RE was not) were expressed and detectable in several parts of the larvae, including the most anterior part of the larvae, which encompasses the chemosensory organs, the brain, and the salivary glands (Fig. 2B). This result indicated that both of the transcription start sites were activated in these different structures, resulting in the presence of all of the transcripts. To confirm that the $\mathrm{P}-\mathrm{Gal} 4$ element insertion in the sano locus caused the gustatory choice behavior defects observed in the sano ${ }^{\text {Gal4 }}$ larvae, we isolated two other transgenic lines containing P-UAS element insertions, which were located $147 \mathrm{bp}$ downstream of the first transcription start site (sano ${ }^{G E 12233}$ ) and 352 bp upstream of the second transcription start site $\left(\right.$ sano $\left.{ }^{G E 15762}\right)$. Homozygous larvae for these P-UAS insertions were viable and showed salt perception defects similar to those observed for the sano ${ }^{\text {Gal4 }}$ mutants (Fig. 1B). Because all of these insertions were located close to the sano gene or in the coding region, they should have disturbed and reduced sano transcription. Accordingly, we measured a significant 3.94-fold decrease of sano expression by qPCR in the sano ${ }^{\text {Gal4 }}$ mutant compared with the wild-type Drosophila (Fig. 2C). When we introduced an UAS-sano construct in a sano ${ }^{\text {Gal4 }}$ mutant background, we induced a significant 4.54 -fold increase in the sano transcript levels (Fig. $2 B$ ). Therefore, the sano ${ }^{\text {Gal }}$ mutant behavioral defects are attributable to the reduction of sano expression and can be rescued inducing sano expression in the sano ${ }^{\text {Gal4 }}$ expressing GRNs.

\section{sano $^{\text {Gal4 }}$ is expressed in the gustatory} neurons required for the aversive response to salt

Several chemosensory organs are located in the anterior part of the larval body (DO, $\mathrm{TO}$, and VO) and along the larval pharynx (dorsal, ventral, and posterior pharyngeal sense organs; Colomb et al., 2007; Gerber
A

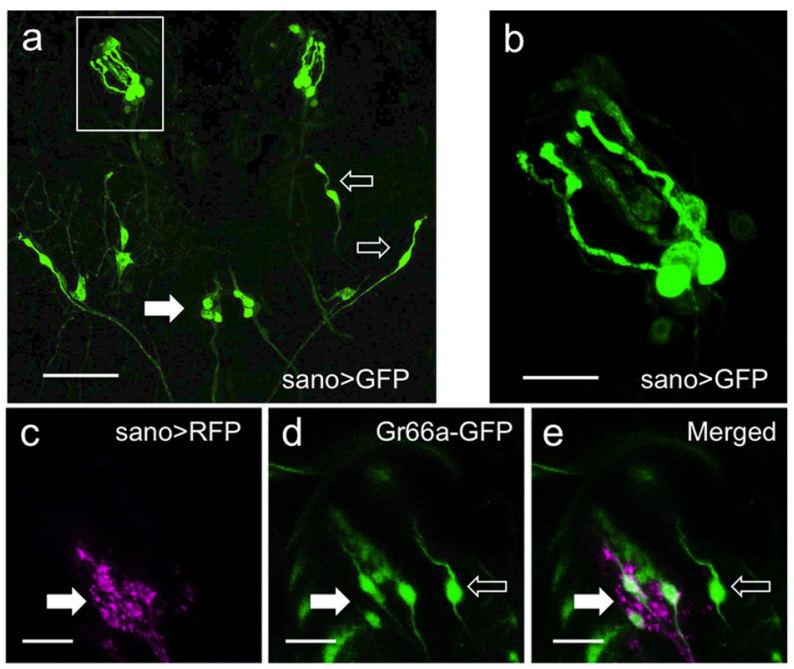

B

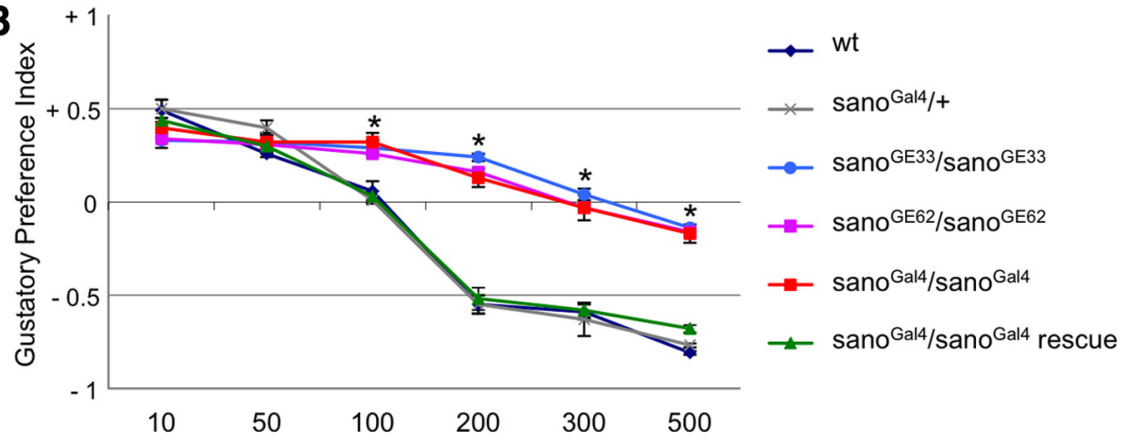

$\mathrm{NaCl}$ concentration $\mathrm{mM}$

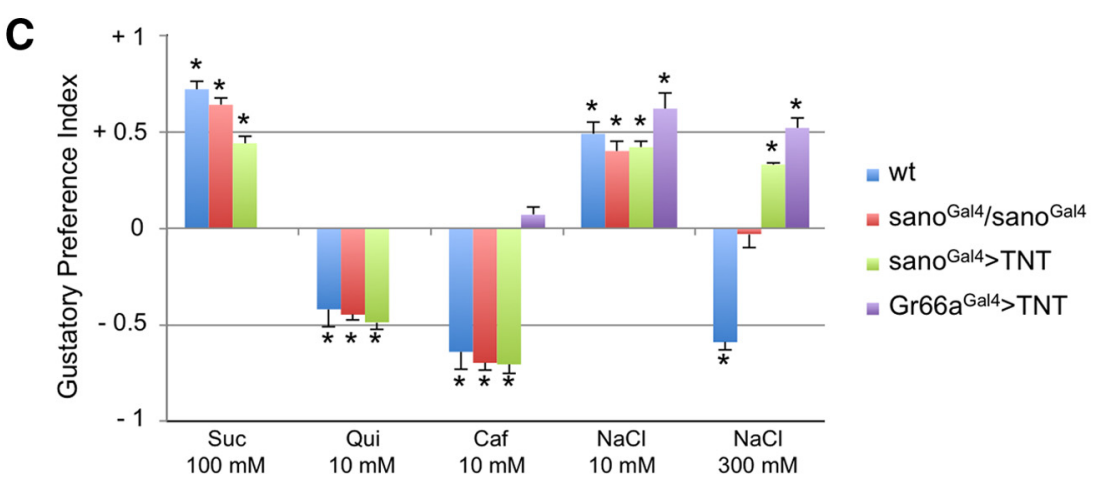

Figure 1. Role of sano in taste perception. $\boldsymbol{A} \boldsymbol{a}, \boldsymbol{A} \boldsymbol{b}$, Ventral view of the anterior part of a third-instar sano $^{\text {Gal4 }} /$ sano $^{\text {Gal4 }}$;10XUAS-IVS-mCD8::GFP/10XUAS-IVS-mCD8::GFP larva. Aa, Expression is observed in gustatory neurons: five neurons in the TO (box) and three neurons in the ventral pharyngeal sense organ (filled arrow). Expression is also present in few neurons along the body (open arrows). Scale bar, $50 \mu \mathrm{m}$. $\boldsymbol{A} \boldsymbol{b}$, Detailed view of the expression in five neurons of the T0. Scale bar, $10 \mu \mathrm{m}$. Ac-Ae, Ventral view of the anterior part of a third-instar sano $0^{6 a / 4} /+; 10 X U A S-/ V S-m C D 8:: R F P / G r 66 a-G F P$ larva. $A c$, sano ${ }^{\text {Gal4 }}$ drives expression of RFP in six neurons of the TO ganglion. Ad, Gr66a-GFP drives expression of GFP in four neurons of the T0 ganglion (filled arrow) and in two adjacent neurons of the T0 dorsolateral group (open arrow). Ae, sano ${ }^{\text {Gal4 }}$ and Gr66a-GFP are coexpressed in four neurons of the $\mathrm{TO}$ ganglion (filled arrow). $B$, Behavioral responses of third-instar larvae to $\mathrm{NaCl}$ concentrations. The GPIs for indicated $\mathrm{NaCl}$ concentrations versus water were calculated. For each condition, 10 trials with 50 larvae were

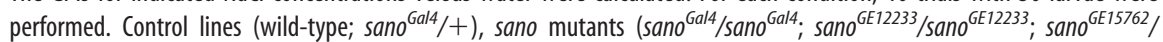
sano $\left.{ }^{G E 15762}\right)$, and the sano rescue line (sano $0^{\text {Gal4 }} /$ sano $^{\text {Gal4 }} ; U A S-$ sano/+) were used in this experiment. Each bar represents a mean \pm SEM of GPI $(n=10)$. Asterisks above error bars indicate that results were significantly different (ANOVA, $p<0.05)$. C, Behavioral responses of third-instar larvae to attractive [ $100 \mathrm{~mm}$ sucrose (Suc) or $10 \mathrm{~mm} \mathrm{NaCl}$ ] or repulsive [10 mm caffeine (Caf), $10 \mathrm{~mm}$ quinine (Qui), or $300 \mathrm{~mm} \mathrm{NaCl}$ ] tastants. Control larvae (wild-type), sano mutant larvae (sano $0^{\text {Gal4 }} / \mathrm{sano}^{\mathrm{Gal} / 4}$ ), and larvae with impaired gustatory neurons (sano $0^{G a / 4}>$ TNT or Gr66a $a^{G a / 4}>$ TNT) were tested. Each point represents the mean \pm SEM of GPI obtained from 10 trials of 50 larvae. A Student's t test comparing with the theoretical value 0 was performed. Asterisks above error bars indicate that results were significantly different $(p<0.05)$. 
A

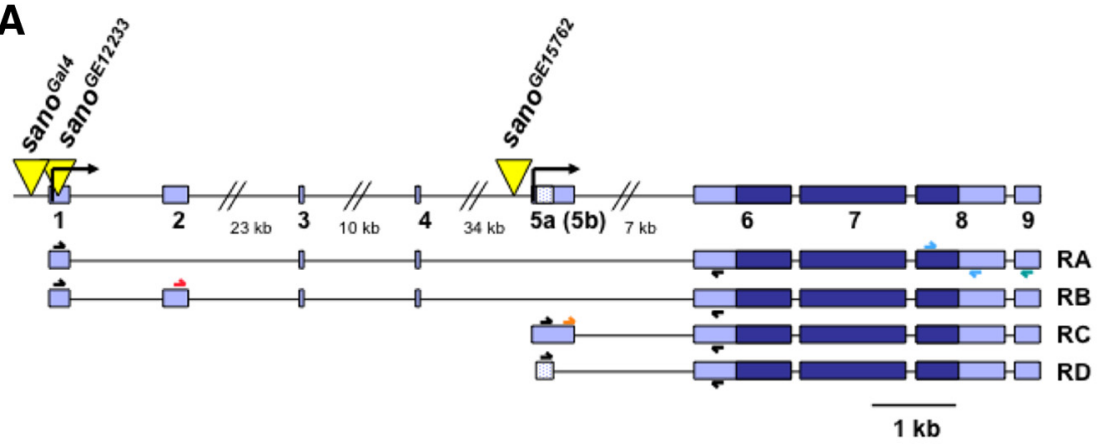

B
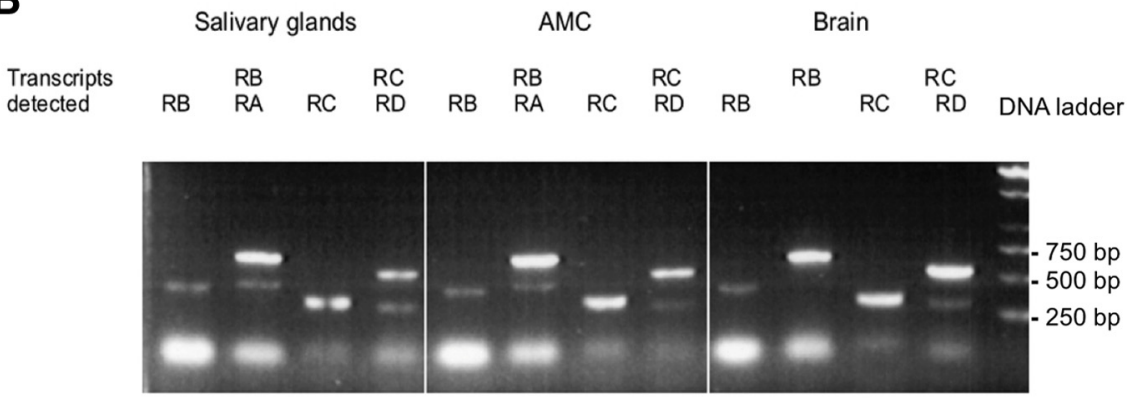

C

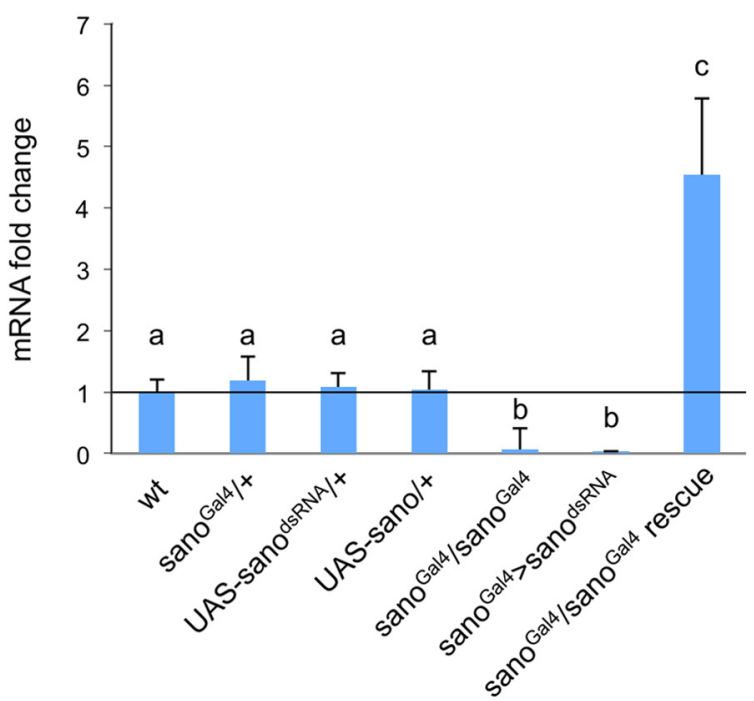

Figure 2. Map and transcript analysis of sano gene. $\boldsymbol{A}$, Structure of the sano gene. Yellow triangles represent the P-element insertions [sano ${ }^{G a / 4}$ is a $P\{G a w B\}$ line, and sano $0^{G E 12233}$ and sano $0^{G E 15762}$ are $P\{U A S\}$ lines]. Exons are shown in blue. Light blue boxes represent the $5^{\prime}$ and $3^{\prime}$ untranslated regions. Scale bar, $1 \mathrm{~kb}$. The arrows above the transcripts indicate the primers used for the RT-PCR analysis. $\boldsymbol{B}$, sano expression analyzed by RT-PCR. RNAs were extracted from the dissected structures of the CantonS larvae. $A P C R$ with a primer specific to the sano sequence was performed to obtain CDNAs by reverse transcription. All of the four transcripts were present in the different organstested. AMC, Antenno-maxillary complex. $C$, The data represent the fold change in the amount of sano transcripts determined by $q P C R$. The CantonS strain was used as the wild-type reference, and the level of wild-type transcripts was defined as 1.0. The error bars represent the SEM, $n=3-10$. The same letter over error bars indicates values that are not significantly different (ANOVA, $p<0.05$ ).

et al., 2009). Previous studies have associated salt detection with the TO (Heimbeck et al., 1999; Liu et al., 2003). When combined with a 10XUAS-IVS-mCD8::GFP transgene, sano ${ }^{\text {Gal4 }}$ expression was detectable in 5.5 neurons of the TO and 3 neurons in the VPS (Fig. $1 A a, A b$ ). To better characterize sano-expressing neurons in the TO, we compared sano ${ }^{\text {Gal }}>$ RFP and Gr66a-GFP expression in larvae. We observed that sano and Gr66a are coexpressed in four neurons, and sano is expressed alone in two neurons in the TO ganglion. Gr66a is expressed alone in two neurons that proj- ect their dendrites to the terminal dome but located in the DO ganglion (TO dorsolateral group; Kwon et al., 2011; Fig. $1 A c-A e)$.

To confirm that sano ${ }^{\text {Gall }}$ is specifically expressed in gustatory neurons involved in high-salt detection, we used an UASTNT transgene to block synaptic transmission and investigate taste perception defects in the presence of attractive or repellent substances (Sweeney et al., 1995; Heimbeck et al., 1999). We tested the behavioral responses of larvae from the sano $^{\text {Gal4 }} \times$ UAS-TNT cross for $100 \mathrm{~mm}$ sucrose, bitter compounds (10 mM caffeine and $10 \mathrm{~mm}$ quinine), and two $\mathrm{NaCl}$ concentrations (10 and $300 \mathrm{~mm}$ ). Mutant larvae showed responses similar to those observed with wild-type larvae toward sucrose, caffeine, quinine, and $10 \mathrm{~mm} \mathrm{NaCl}$ (Fig. 1C). However, mutant larvae showed an avoidance defects toward $300 \mathrm{~mm} \mathrm{NaCl}$ (Fig. 1C). More intriguingly, sano ${ }^{\text {Gal4 }} \times$ UAS-TNT larvae showed the same response toward low- and high- $\mathrm{NaCl}$ concentrations; they were also attracted by high-salt concentration. We also tested the behavioral responses of larvae from the Gr66a $a^{\text {Gal4 }} \times U A S-T N T$ cross for 10 $\mathrm{mM}$ caffeine and low- and high- $\mathrm{NaCl}$ concentrations. Mutant larvae show no preference for caffeine as expected and attraction to low-salt concentration. Surprisingly, they also showed an attraction to high- $\mathrm{NaCl}$ concentration (Fig. 1C). Our results showed that the inactivation of neural transmission in the Gr66a ${ }^{\text {Gal4 }}$-expressing neurons can block the avoidance to caffeine and high-salt concentrations, whereas blocking neural transmission in the sano ${ }^{\text {Gal4 }}$-expressing neurons specifically blocked the avoidance toward high$\mathrm{NaCl}$ concentration.

sano is involved in high-salt perception To confirm the role of sano in salt perception, we generated transgenic lines containing a dsRNA construct that included part of exon 7. This construct was intended to induce the degradation of all the sano transcripts. When we activated the expression of this sano ${ }^{d s R N A}$ construct using sano ${ }^{\text {Gal }}$ as a driver, we observed a fivefold decrease of sano mRNA levels detected by a qPCR analysis on dissected anterior parts of larvae (Fig. 2C). We then tested the ability of larvae expressing sano ${ }^{d s R N A}$ to discriminate between attractive or repellent compounds. As predicted, larvae from the sano ${ }^{\text {Gal }} \times U \times$ US-sano $^{d s R N A}$ cross showed responses similar to the wild-type larvae toward $10 \mathrm{~mm}$ $\mathrm{NaCl}, 10 \mathrm{~mm}$ sucrose, and $10 \mathrm{~mm}$ caffeine (Fig. $3 A$; data not shown). Similarly, larvae from the elav ${ }^{\text {Gal4 }} \times U A S-$ sano $^{d s R N A}$ cross and Gr66a $a^{\text {Gal4 }} \times U A S-s a n o^{d s R N A}$ cross also showed responses similar to the wild-type larvae toward $10 \mathrm{~mm} \mathrm{NaCl}, 10$ 
mM sucrose, and $10 \mathrm{~mm}$ caffeine (Fig. $3 A$; data not shown). In the presence of 300 $\mathrm{mM} \mathrm{NaCl}$, larvae expressing UAS-sano ${ }^{d}$. sRNA in sano ${ }^{\text {Gal4 }}$ or Gr66a $a^{\text {Gal4 }}$ neurons or all the neurons showed an attractive response, whereas wild-type larvae showed an aversive response (Fig. 3A). These results are similar to the response obtained when neural transmission is blocked by expressing TNT in sano ${ }^{\text {Gal4 }}$ - or Gr66a $a^{\text {Gal4 }}$ expressing neurons.

To show that the gustatory choice behavior defects observed for the sano mutant could be attributable to a late disruption of sano expression during the third-larval instar, we investigated the effect of a temporal controlled inactivation of sano expression on $\mathrm{NaCl}$ perception. We performed temperature-shifting experiments on larvae bearing sano ${ }^{\text {Gal4 }}$, a sano ${ }^{d s R N A}$ construct, and a tubP-Gal80 ${ }^{\text {ts }}$ transgene. The Gal80 ${ }^{\text {ts }}$ protein can interact with and block Gal4 at low temperatures $\left(19^{\circ} \mathrm{C}\right)$ but is inactivated at a higher temperature $\left(30^{\circ} \mathrm{C}\right)$, allowing the Gal4 protein to activate sano ${ }^{d s R N A}$ expression (McGuire et al., 2003). When the larvae were reared at $19^{\circ} \mathrm{C}$, sano ${ }^{d s R N A}$ was not expressed, and we observed an aversive response of the larvae to $300 \mathrm{~mm} \mathrm{NaCl}$ similar to the wild-type response (Fig. $3 B)$. When the larvae were transferred to $30^{\circ} \mathrm{C}$ overnight before the tests, sano ${ }^{d s R N A}$ expression is activated and larvae showed behavioral defects toward highsalt concentrations (Fig. 3B). Larvae showed an attractive response similar to that observed for the larvae from the sano $^{\text {Gal4 }} \times U A S-$ sano ${ }^{d s R N A}$ cross. These results suggest that sano is expressed during the third-larval instar and is required for the activity of the gustatory neurons that detect high-salt concentrations.

Thus, the reduction of sano expression in sano Gal4 - or $G r 66 a^{\text {Gal4 }}$-expressing gustatory neurons or in the whole nervous system led to a similar disruption of high$\mathrm{NaCl}$ perception in larvae.

ppk19 is involved in low- and high-salt perception

ppk19 has been implicated in the perception of both low- and high- $\mathrm{NaCl}$ concentration at larval instar (Liu et al., 2003). In our behavioral tests, we showed that expression of a $p p k 19^{d s R N A}$ construct in all the neurons using an elav ${ }^{\text {Gal4 }}$ driver led to the absence of a preference toward low- or high- $\mathrm{NaCl}$ concentrations (Fig. $3 A)$. The expression of $p p k 19^{d s R N A}$ using sano ${ }^{\text {Gal4 }}$ or Gr66a $a^{\text {Gal4 }}$ did not affect the attraction toward $10 \mathrm{~mm} \mathrm{NaCl}$ (Fig. $3 A$ ). However, disruption of $p p k 19$ in sano ${ }^{\text {Gal4 }}$ neurons induced an attractive response to $300 \mathrm{~mm} \mathrm{NaCl}$ (Fig. $3 A$ ). Thus, loss of ppk19 in sano ${ }^{\text {Gal4 }}$ or $\mathrm{Gr}_{66 a^{\text {Gal4 }}}$ neurons only impaired avoidance to high- $\mathrm{NaCl}$ concentration but not attraction attributable to low-salt perception.
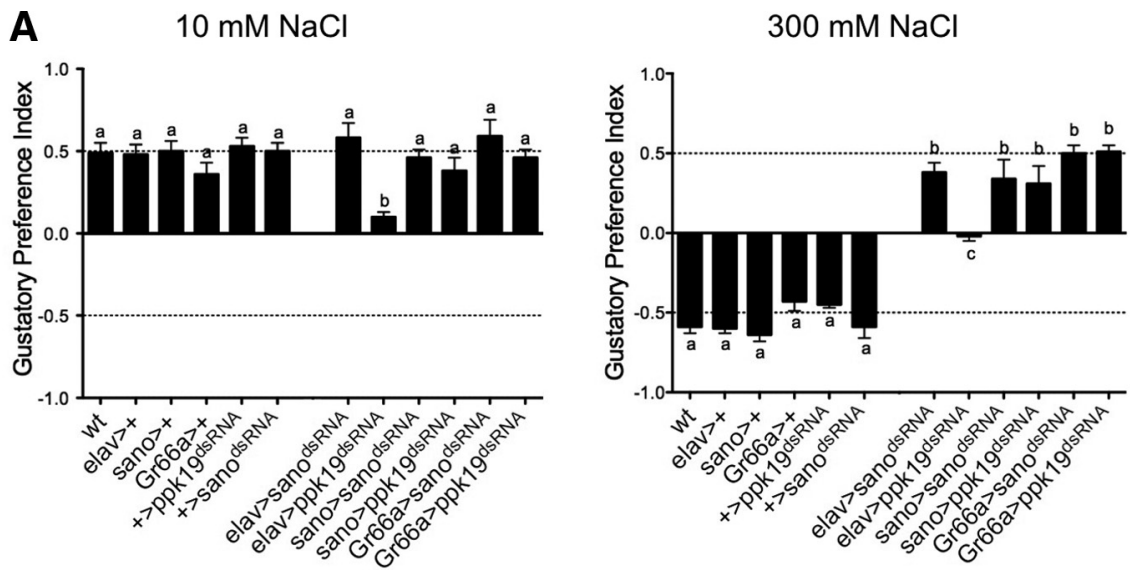

B

C

High $\mathrm{NaCl}$ response

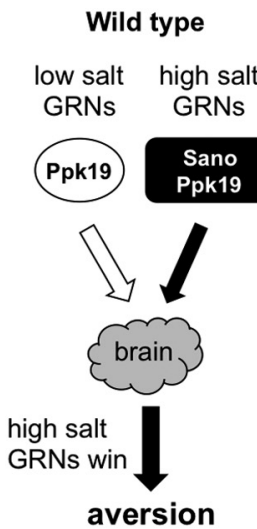

sano mutant

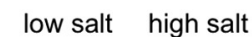
GRNs GRNs
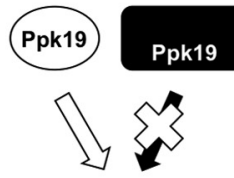

a

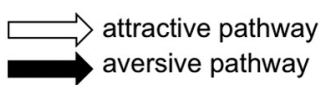

Figure 3. Disruption of sano and ppk19 by dsRNA. $\boldsymbol{A}$, Behavioral assay for $10 \mathrm{~mm} \mathrm{NaCl}$ and $300 \mathrm{~mm} \mathrm{NaCl}$. The effects of sano or pk19 disruption in all larval neurons (elav ${ }^{\text {Gal4 }}$ crosses), sano-expressing neurons (sano ${ }^{G a / 4}$ crosses), or Gr66a-expressing neurons (mere tested in these experiments. Each histogram (mean \pm SEM of GPI) was calculated from 10 trials. The same in of Sano on aversive behavior at $300 \mathrm{~mm} \mathrm{NaCl}$. Two temperature conditions were used. The offspring from the crosses tubP-Gal80 ${ }^{\text {ts }}$, sano $>$ sano ${ }^{d s R N A}$ larvae. When $t u b P-G a l 80^{\text {ts }}$, sano $>$ sano ${ }^{d s R N A}$ larvae are transferred to a permissive temperature of $30^{\circ} \mathrm{C}$ overnight $(0 / \mathrm{N})$, sano $0^{\text {Gal4 }}$ drives expression of sano ${ }^{d s R N A}$. Each histogram (mean $\pm \mathrm{SEM}$ of GPI) was calculated from 10 trials. showing that the loss of Sano selectively impairs the aversive salt taste pathway. ppk19 is required in both low-and high-salt GRNs detect $\mathrm{NaCl}$. sano is required in high-salt GRNs to detect high- $\mathrm{NaCl}$ concentrations. In wild-type context, both low-and high-salt GRNs are activated by high- $\mathrm{NaCl}$ concentration, leading to aversion. Loss of sano selectively disrupts the aversive pathway, leading to attraction in the presence of high- $\mathrm{NaCl}$ concentration.

\section{Sano and PPK19 regulate the neuronal activity of taste neurons}

To provide physiological evidence showing that sano is required for $\mathrm{NaCl}$ detection, a calcium-sensitive protein, Cam2.1, was expressed in larval taste neurons to monitor $\mathrm{Ca}^{2+}$ levels in response to $\mathrm{NaCl}$ (Diegelmann et al., 2002). Expression of this protein was driven by the sano ${ }^{\text {Gal }}$ line and was thus expressed in a subset of neurons in the TO (Fig. 1A). Fluorescence levels were analyzed in the cell bodies of these neurons in the TO that expressed the Cam2.1 protein. This allowed for the precise analysis of the calcium levels after stimulation with different concentrations of $\mathrm{NaCl}$. In wild-type larvae, when a solution of $20 \mathrm{~mm} \mathrm{NaCl}$ was applied, a variation of fluorescence was observed that was not significantly different from the variation observed in the controls without $\mathrm{NaCl}$ (Fig. 4). With the application of a $300 \mathrm{~mm} \mathrm{NaCl}$ 
A

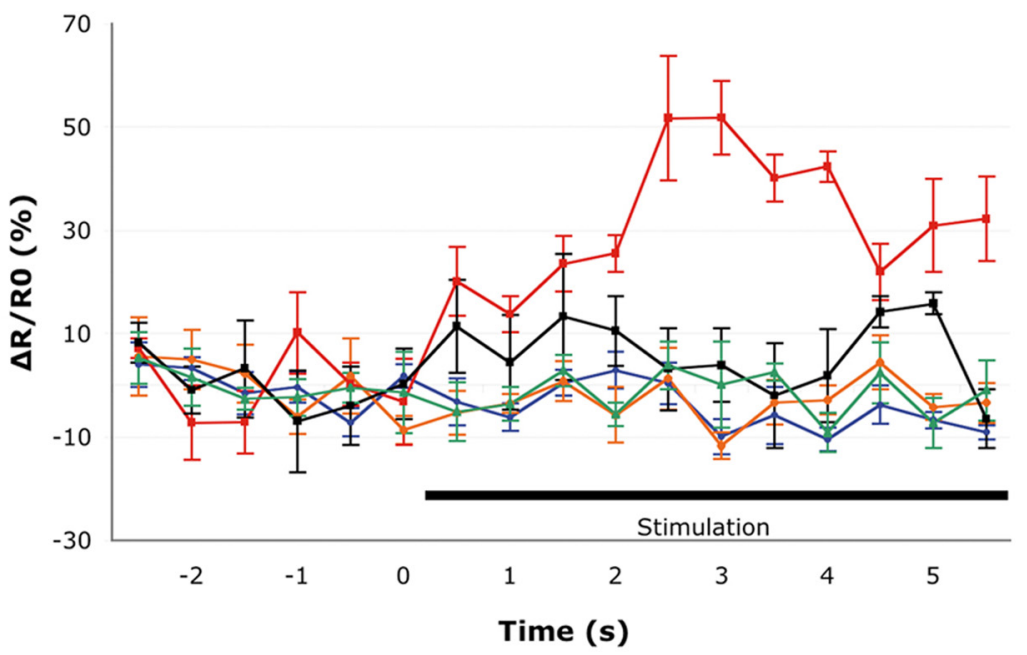

B

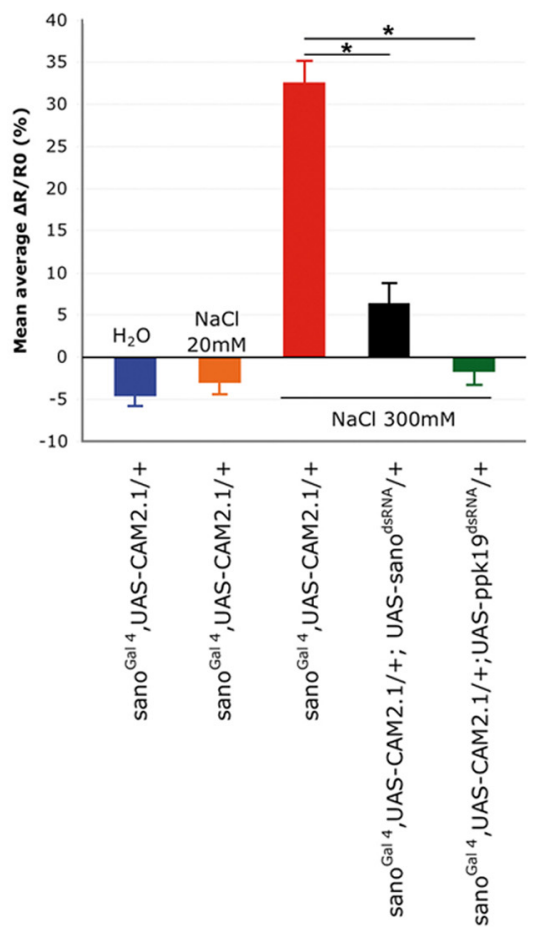

\section{C}
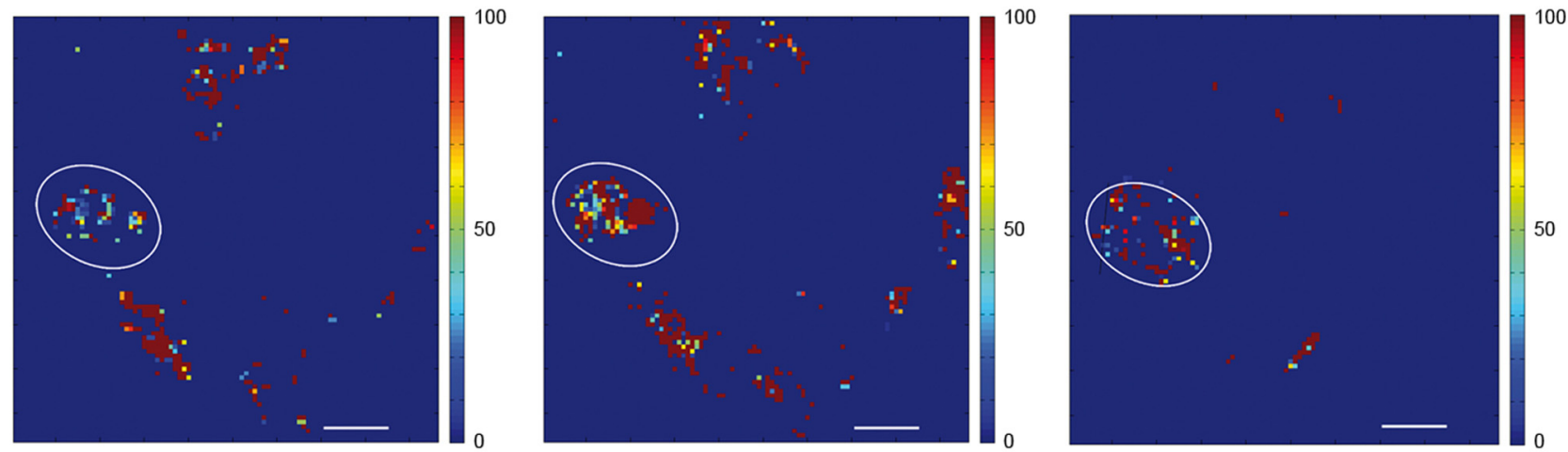

Figure 4. Sano and PPK19 are required for TO neuron activation by high-NaCl concentrations. $A$, Representative fluorescence change $(\Delta R / R 0)$ of CAM2.1 expressed in sano $0^{\text {Gal4 }}$ neurons in control and mutant larvae. Neuronal activity was measured before and after the addition of different stimuli: distilled water, $20 \mathrm{~mm} \mathrm{NaCl}$, or $300 \mathrm{~mm} \mathrm{NaCl}$. Responses to $300 \mathrm{~mm} \mathrm{NaCl}$ were measured in larvae expressing either sano ${ }^{d s R N A}$ or ppk $19^{d s R N A}$ in sano ${ }^{G a l 4}$ neurons $(n=4-6)$. The error bars represent the SEM. $\boldsymbol{B}$, Mean FRET ratio changes. Changes were measured during the first $5 \mathrm{~s}$ of the stimulation of different control and mutant larvae $(n=4-6)$. The error bars represent the SEM. Asterisks indicate that results are significantly different (Student's $t$ test, $p<0.05)$. C, Peak responses are shown in false-color scale ( $\triangle R / R 0 \%$, right of images). Left, sano ${ }^{G A L 4}$, UAS-CAM2.1/+ before stimulation. Middle, sano ${ }^{\text {GAL4 }}$, UAS-CAM2.1/+ at 2 safter stimulation with $300 \mathrm{~mm} \mathrm{NaCl}$. Right, sano ${ }^{\text {GAL4 }}$, UASCAM2.1/+;UAS--sano dsRNA $/+$ at $2 \mathrm{~s}$ after stimulation with $300 \mathrm{~mm} \mathrm{NaCl}$. The cell bodies of the neurons used for the FRET measurements are circled. Scale bar, $10 \mu \mathrm{m}$.

solution, a significant increase (50\%) of the fluorescence was observed after $2 \mathrm{~s}$ of exposure. This result indicated that the observed neurons were sensitive to a high concentration of $\mathrm{NaCl}$ and respond to an increase of the $\mathrm{Ca}^{2+}$ level. To determine the role of sano and ppk19 in the activation of these neurons, an UAS-sano $o^{d s R N A}$ or a UAS-ppk $19^{d s R N A}$ construct was then introduced into the $\operatorname{sano}^{\text {Galt }}$;UAS-Cam2.1 background. In these two genetic contexts, the signal-to-noise level remained low after the addition of a $300 \mathrm{~mm} \mathrm{NaCl}$ solution and close to the control levels in the neurons stimulated by high- $\mathrm{NaCl}$ concentrations. These data showed that PPK19 and Sano are required in sano ${ }^{\text {Gal4 }}$ neurons to induce an increase of the intracellular calcium levels in response to high- $\mathrm{NaCl}$ concentrations. Therefore, PPK19 and Sano are both required for the activity of gustatory neurons in the TO that are involved in the detection of high-salt concentrations.

\section{Discussion}

sano is expressed in the neurons that detect

\section{high-salt concentrations}

Our behavioral results on larvae showed that sano ${ }^{\text {Gal }}$ is expressed in a group of GRNs in the TO that are specifically involved in the detection of high- $\mathrm{NaCl}$ concentrations. Because sano and Gr66a are coexpressed in four neurons in the TO, we propose that these neurons are specifically required for high-salt detection. The attractive behavioral response of larvae observed when these neurons are inactivated showed that other gustatory neurons are still 
able to detect $\mathrm{NaCl}$. This result strongly suggests that two distinct types of neurons respond simultaneously to either low- or highsalt concentrations to generate an attractive or aversive response (Fig. 3C). Recently, Zhang et al. (2013) proposed a model in which competition between low-salt GRNs and high-salt GRNs in S- and L-type sensilla results in the bidirectional behavioral responses to salt in adults. They showed that loss of Ir76b selectively disrupted the attractive salt pathway and left the aversive salt pathway intact, leading to an aversive response to low-salt concentrations. In our experiments, we observed that inactivation of sano-expressing GRNs induced an attraction to high-salt concentrations, suggesting that the aversive salt pathway is disrupted and the attractive salt pathway remained unaffected. Thus, we conclude that, in larvae as in adults, a bimodal switch system determines the opposing behavioral responses to low- and high-salt; sano is only expressed in the neurons of the aversive salt pathway.

Previous results have demonstrated that the TO shows only weak electrophysiological responses to $100 \mathrm{~mm} \mathrm{NaCl}$ (Oppliger et al., 2000). Here, using the FRET technique, we showed that the sano-expressing neurons are strongly stimulated by $300 \mathrm{~mm} \mathrm{NaCl}$ but not by a low concentration of $\mathrm{NaCl}$. Therefore, sano ${ }^{\text {Gal }}$ neurons are involved in the detection of high$\mathrm{NaCl}$ concentrations in larvae. Thus, the sano ${ }^{\text {Galt }}$ line is characteristic of larval sensory neurons required for the perception of high- $\mathrm{NaCl}$ concentrations and provides an excellent genetic tool to specifically target these neurons for additional cellular and molecular study.

\section{Disruption of sano impairs the aversive response to high- $\mathrm{NaCl}$ concentrations}

Larvae with impaired sano function display behavioral defects in the presence of high-salt concentrations. Tests performed with caffeine and quinine provided evidence that the sano mutant larvae were able to detect and avoid other aversive molecules, suggesting that Sano does not play a role in the detection of aversive molecules in general. Attractive behaviors to sucrose or low-salt concentrations were also not affected. Similarly, the disruption of Sano function using UAS-sano ${ }^{d s R N A}$ constructs under the control of sano ${ }^{\text {Gal4 }}$, Gr66 $^{\text {Gal4 }}$, or elav ${ }^{\text {Gal4 }}$ only caused the loss of high-salt detection in larvae. Thus, the disruption of Sano throughout the whole nervous system or in a subset of GRNs (including bitter GRNs) only affects the perception of high- $\mathrm{NaCl}$ concentrations.

Studies on the ppk gene family have shown that PPK19 is required for the detection of low- and high-salt concentrations (Liu et al., 2003). Our results highlight the particular role of Sano in the detection of high- $\mathrm{NaCl}$ concentrations; thus, the sano gene is the first characterized gene specifically required for an aversive response to salt.

\section{Sano is involved in the activity of high-salt larval GRNs}

Little is known about the cellular mechanisms of salt detection by GRNs. Here, we identified a protein that appears to be cytoplasmic and is part of the cellular mechanism required in high-salt detecting neurons. In mammals, intracellular calcium levels are modulated in response to chemosensory stimuli, such as salt, in taste-receptor cells (Chandrashekar et al., 2010). In Drosophila, calcium imaging has been used in adults to measure neuronal activity in response to sugars, bitter substances, and $\mathrm{NaCl}$ (Marella et al., 2006). Our results show that calcium levels are increased in sano-expressing neurons in the TO in response to high-salt concentrations. This increase in GRN activity requires PPK19 and Sano. Then Sano is involved in the detection of high salt by GRNs in the TO.

Previous studies have shown that Sano is a cytoplasmic protein that interacts with other proteins, such as Grb2 (a protein involved in the signaling pathways of tracheal and wing development; Chung et al., 2009). Moreover, a molecular interaction with Epac (exchange protein directly activated by cAMP) has been detected in a two-hybrid study (Giot et al., 2003). Epac is a member of the Rap1 signal transduction pathway and is involved in cell adhesion and differentiation, as well as in neuronal activity by regulating calcium levels or neurotransmitter release (Gloerich and Bos, 2010). The genetic and molecular interactions between Sano and Epac remain to be fully demonstrated by future in vitro and in vivo studies and may provide new insights into the cellular mechanisms taking place downstream of the DEG/ $\mathrm{ENaC}$ channels in salt-detecting neurons.

\section{References}

Amrein H, Thorne N (2005) Gustatory perception and behavior in Drosophila melanogaster. Curr Biol 15:R673-R684. CrossRef Medline

Balakireva M, Gendre N, Stocker RF, Ferveur JF (2000) The genetic variant Voila causes gustatory defects during Drosophila development. J Neurosci 20:3425-3433. Medline

Chandrashekar J, Kuhn C, Oka Y, Yarmolinsky DA, Hummler E, Ryba NJ, Zuker CS (2010) The cells and peripheral representation of sodium taste in mice. Nature 464:297-301. CrossRef Medline

Chung S, Vining MS, Bradley PL, Chan CC, Wharton KA Jr, Andrew DJ (2009) Serrano (sano) functions with the planar cell polarity genes to control tracheal tube length. PLoS Genet 5:e1000746. CrossRef Medline

Colomb J, Grillenzoni N, Ramaekers A, Stocker RF (2007) Architecture of the primary taste center of Drosophila melanogaster larvae. J Comp Neurol 502:834-847. CrossRef Medline

Diegelmann S, Fiala A, Leibold C, Spall T, Buchner E (2002) Transgenic flies expressing the fluorescence calcium sensor Cameleon 2.1 under UAS control. Genesis 34:95-98. CrossRef Medline

Gerber B, Stocker RF (2007) The Drosophila larva as a model for studying chemosensation and chemosensory learning: a review. Chem Senses 32: 65-89. CrossRef Medline

Gerber B, Stocker RF, Tanimura T, Thum AS (2009) Smelling, tasting, learning: Drosophila as a study case. Results Probl Cell Differ 47:139-185. CrossRef Medline

Giot L, Bader JS, Brouwer C, Chaudhuri A, Kuang B, Li Y, Hao YL, Ooi CE, Godwin B, Vitols E, Vijayadamodar G, Pochart P, Machineni H, Welsh M, Kong Y, Zerhusen B, Malcolm R, Varrone Z, Collis A, Minto M, et al. (2003) A protein interaction map of Drosophila melanogaster. Science 302:1727-1736. CrossRef Medline

Gloerich M, Bos JL (2010) Epac: defining a new mechanism for cAMP action. Annu Rev Pharmacol Toxicol 50:355-375. CrossRef Medline

Heimbeck G, Bugnon V, Gendre N, Häberlin C, Stocker RF (1999) Smell and taste perception in Drosophila melanogaster larva: toxin expression studies in chemosensory neurons. J Neurosci 19:6599-6609. Medline

Hiroi M, Meunier N, Marion-Poll F, Tanimura T (2004) Two antagonistic gustatory receptor neurons responding to sweet-salty and bitter taste in Drosophila. J Neurobiol 61:333-342. CrossRef Medline

Ishimoto H, Tanimura T (2004) Molecular neurophysiology of taste in Drosophila. Cell Mol Life Sci 61:10-18. CrossRef Medline

Johnson AL, Aravind L, Shulzhenko N, Morgun A, Choi SY, Crockford TL, Lambe T, Domaschenz H, Kucharska EM, Zheng L, Vinuesa CG, Lenardo MJ, Goodnow CC, Cornall RJ, Schwartz RH (2009) Themis is a member of a new metazoan gene family and is required for the completion of thymocyte positive selection. Nat Immunol 10:831-839. CrossRef Medline

Kwon JY, Dahanukar A, Weiss LA, Carlson JR (2011) Molecular and cellular organization of the taste system in the Drosophila larva. J Neurosci 31: 15300-15309. CrossRef Medline

Lee YS, Carthew RW (2003) Making a better RNAi vector for Drosophila: use of intron spacers. Methods 30:322-329. CrossRef Medline 
Liu L, Leonard AS, Motto DG, Feller MA, Price MP, Johnson WA, Welsh MJ (2003) Contribution of Drosophila DEG/ENaC genes to salt taste. Neuron 39:133-146. CrossRef Medline

Marella S, Fischler W, Kong P, Asgarian S, Rueckert E, Scott K (2006) Imaging taste responses in the fly brain reveals a functional map of taste category and behavior. Neuron 49:285-295. CrossRef Medline

McGuire SE, Le PT, Osborn AJ, Matsumoto K, Davis RL (2003) Spatiotemporal rescue of memory dysfunction in Drosophila. Science 302:17651768. CrossRef Medline

Nakamura M, Baldwin D, Hannaford S, Palka J, Montell C (2002) Defective proboscis extension response (DPR), a member of the Ig superfamily required for the gustatory response to salt. J Neurosci 22:3463-3472. Medline

Niewalda T, Singhal N, Fiala A, Saumweber T, Wegener S, Gerber B (2008) Salt processing in larval Drosophila: choice, feeding, and learning shift from appetitive to aversive in a concentration-dependent way. Chem Senses 33:685-692. CrossRef Medline

Oppliger FY, Guerin PM, Vlimant M (2000) Neurophysiological and be- havioural evidence for an olfactory function for the dorsal organ and a gustatory one for the terminal organ in Drosophila melanogaster larvae. J Insect Physiol 46:135-144. CrossRef Medline

Rubin GM, Spradling AC (1982) Genetic transformation of Drosophila with transposable element vectors. Science 218:348-353. CrossRef Medline

Russell C, Wessnitzer J, Young JM, Armstrong JD, Webb B (2011) Dietary salt levels affect salt preference and learning in larval Drosophila. PLoS One 6:e20100. CrossRef Medline

Sweeney ST, Broadie K, Keane J, Niemann H, O’Kane CJ (1995) Targeted expression of tetanus toxin light chain in Drosophila specifically eliminates synaptic transmission and causes behavioral defects. Neuron 14: 341-351. CrossRef Medline

Vosshall LB, Stocker RF (2007) Molecular architecture of smell and taste in Drosophila. Annu Rev Neurosci 30:505-533. CrossRef Medline

Zhang YV, Ni J, Montell C (2013) The molecular basis for attractive salttaste coding in Drosophila. Science 340:1334-1338. CrossRef Medline 